\title{
GLOBAL GOVERNANCE OF THE TECHNOLOGICAL REVOLUTION
}

\author{
Emilio Mordini \\ Centre for Science, Society and Citizenship, Rome, IT \\ People who confuse science with technology tend to become confused \\ about limits, they imagine that new knowledge always means new know- \\ how, some even imagine that knowing everything would let us do anything. \\ - E.Drexler
}

\begin{abstract}
This paper discusses governance challenges of technologies emerging from the information technology (IT) and biotechnology revolutions. Of particular interest here are electronic communication and intelligent computing environments, emerging from the information revolution, and human genetic manipulation and bioinformatics, emerging from the biotechnology revolution. These technologies amplify human capabilities so significantly and profoundly that they stand to alter fundamentally the very notion of what we think of as human. How policy makers respond to the challenges these technologies pose, including the extent to which developments are supported with public research funds and whether they are regulated, is a matter of increasing concern among citizens and for governing bodies. New governance mechanisms, particularly on an international level, may be needed to address emerging issues.
\end{abstract}

Keywords; Governance, Ethics, Information, Technology, Biotechnology, Public Policies

\section{INTRODUCTION}

A scene in "Blade Runner", a 1980s science fiction movie, is set in the headquarters of a prosperous-looking biotechnology company. The firm makes "replicants", robots that look like humans, and the firm's boss describes how they are grown from a single cell. The replicants are genetically modified people without any legal rights. In this dystopia, it is the unaltered humans who rule. By contrast, "GATTACA", another movie set in a genetically modified future, has the modified in charge. They are 
beautiful, gifted and intelligent. It is those who remain untouched by modification who suffer. All this is in the realm of fiction, but the contrasting views of the potential effects of biotechnology point to an important truth about any technology. What really matters is not what is possible, but what people make of those possibilities.

Technology is the practical application of knowledge to perform some actions, to solve some practical problems, or to achieve some practical goals. Technology puts moral intuitions to the test. While knowledge has always a positive value - at least in liberal, open societies - its practical applications often need to be regulated. Policy makers should obviously be open-minded about these regulations, but be cautious and questioning as well. History has taught us that worrying much about technological change rarely stops it, it does not mean, however, that one should give up trying to govern it.

\section{GOVERNANCE}

Governance is the effort of human communities to try to control, direct, shape, or regulate certain kinds of activities. The governance approach implies that conventional boundaries between politics, policies and administration become less significant than the question of how the whole ensemble works (or fails to work). In this sense, governance is a broader notion referring to the act of running a government, state, regime, etc., that encompasses and transcends that of government. It is a process of management and control involving several actors, and, specifically, of interaction between formal institutions and those of civil society.

Governance may be viewed from two angles, in terms of effectiveness and of the results it aims to achieve, and from an ethical point of view, in terms of the fairness and inclusiveness of the process. From the first perspective, an effective political system - considered as any system in which supra-individual decisions must be taken and implemented - can lead to increased participation on the part of the actors involved in the decisionmaking process. Thus it can result in increasing the motivation on the part of citizens as active members of the "community". Thinking ethically, the idea of governance is based on the principles of fairness and transparency that should imbue any bureaucratic or political procedure in a democratic society (Koenig, 1999).

The European Commission's White Paper on European Governance lists five principles which should underpin good governance: openness, participation, accountability, effectiveness and coherence. Ideally, good governance should aim to ensure a high level of participation, and a fair, transparent and effective decision-making and implementation process, 
contributing to raising the level of confidence. (European Commission, 2001) This seems by and large to agree with the definition of governance provided by the World Bank, according to which "good governance is epitomised by predictable, open and enlightened policy-making, a bureaucracy imbued with a professional ethos acting in furtherance of the public good, the rule of law, transparent processes, and a strong civil society participating in public affairs.” (GDRC)

\section{TECHNO REVOLUTION}

The enormous growth of modern technology (esp., information and biotechnology) over the late $20^{\text {th }}$ century has provided the basis for myriad applications in industry, agriculture, and medicine. This ever-expanding research activity is resulting in numerous discoveries that are transforming human life and societies. Technological revolution coupled with global electronic networks of exchange of capital, knowledge, commodities, and information has created a key feature of the globalisation era: a short circuit between scientific discovery and its technological application. Today, the time between new discoveries and their applications has shortened as public opinion and policy makers are often incapable to form a clear picture of what is worth worrying about. They often end up wavering between a naive enthusiasm mixed up with scientific hubris on one side and blind fear of the new on the other. This is why governance of science and technology policy is becoming increasingly important.

IT and biological technologies are post-modern technologies, in the sense that they are de-centred, dispersed and disseminated, and their control and use are largely in the hands of the individuals, citizens' groups, and small enterprises. Namely, they are network technologies. In comparison with technologies that drove the industrial revolution - which were complex, based on collective action, social infrastructure, and technical know-how IT and biotechnologies are lighter. The governance challenge is no longer democratic control over centralized systems - as it was in the 20th century, with such technologies as nuclear weaponry and energy, telecommunications, pharmaceuticals, medicine, and airlines-but governance over decentralised, distributed systems.

The current political and legal infrastructures - shaped on "hard" technology - are inadequate for dealing with global changes in IT and biotechnology. There are three main oppositions that characterise postmodern technology: (1) global vs. local, (2) public vs. private, and, (3)use vs. misuse. 
The opposition between global and local is vital to understand the particular perspective from which new technologies look at globalisation. Glocalisation is a neologism invented to describe a strategy which addresses the issues of globalisation by empowering local communities. "In short, the word "glocalisation" is meant to point to a strategy involving a substantial reform of the different aspects of globalisation, with the goal being both to establish a link between the benefits of the global dimension - in terms of technology, information and economics - and local realities, while, at the same time, establishing a bottom-up system for the governance of globalisation, based on greater equality in the distribution of the planet's resources and on an authentic social and cultural rebirth of disadvantaged populations." (CERFE, 2003).

New technologies are inherently "glocal" because they empower individuals and common interest groups. The fact that collective action is not required to use these technologies makes them particularly difficult to be controlled by national governments. The Internet is often cited as a promoter of "true democracy" because it enables the individual to interact with others directly and in real time. New technologies, such as the GRID and evolving intelligent user-oriented computing environments based upon it, hold promises to go further. The Grid refers to an infrastructure that enables the integrated, collaborative use of high-end computers, networks, databases, and scientific instruments owned and managed by multiple organizations. Grid is a system that: 1) coordinates resources that are not subject to centralized control; 2) using standard, open, general-purpose protocols and interfaces 3) to deliver nontrivial qualities of service. (Foster J., 2003). Distributed Computing lets people share computing power, databases, and other on-line tools securely across corporate, institutional, and geographic boundaries without sacrificing local autonomy.

Biotechnology, too, is seen as having special promise because it will tailor treatments and medicines to the individual and place emphasis of certain biological controls on processes in the hands of individuals. For example, communications in the user's context with bio-sensors (such as in intelligent human-collaborative spaces) which is not too distant. Biotechnology companies are often local in their dimensions but global in their strategies.

Agricultural biotechnology is going to lead the market. The area planted with genetically modified crops now amounts to almost $60 \mathrm{~m}$ hectaresadmittedly only $4 \%$ of the world's arable land, but a $12 \%$ increase on the year before. Where GM strains of a crop species are available, they are starting to dominate plantings of that species. Half the world's soybean crop is genetically modified. And three-quarters of those who plant GM crops are farmers in the poor world. Farmers, on the other hand, can see the virtue of 
paying a bit more for their seed if that allows them to use fewer chemicals and to enhance the nutritional qualities of crops.

Medical biotechnology is overturning the drug market. Genomics provides opportunities to predict responsiveness to drug interventions, since variations in these responses are often attributable to the genetic endowment of the individual. In the long term, it promises to individualise prescription practices by narrowing the target populations exclusively to those for which the medication is safe and effective. Industrial biotechnology, coupled with nanotechnology, promises to create completely new products. What is astonishing is that this revolution is happening through networks of small, medium enterprises, often localised in emerging countries.

The tension between private and public realms is the other key opposition to understand the technological revolution. IT and biotechnology participate in the post-modern tendency of a reduction of public space and regulation, in favour of private, individual or community oriented spheres. The question of the distinction between public and private is likely to be one of the main political issues of this revolution. It's a problem that it directly concerns its legal framework. The private/public distinction comes from moral and political theory. Private conduct may be seen as somewhat outside the scope of law. The private realm is the realm of morality, where actions are not judged according to the law. Liberal political theory made essential use of mis category in assessing the permissible sphere of the law. In the Internet world, it is quite impossible to distinguish seriously between public and private spheres. The two spheres fade and overlap. The Internet teaches that little is "illegal" but that everything is possible, and even fair, from the moment that it can be found on the World Wide Web. To some extent, we support almost a growing anti-legal consideration of human actions. Through the Internet, the private sphere becomes global. The Internet has evolved into a global information network and has developed beyond its original purpose of sharing information into a global commercial trading system where everything can be purchased: human cloning, organs to be transplanted, viruses that can be weaponised. Procedures that are judged ethically or medically objectionable in one country may become available elsewhere through market mechanisms, leading to the development of foreign sites where individuals may go to avoid regulations. The development of biotechnology products requires extensive social and technical know-how but does not necessarily require a large infrastructure to be deployed. It is not clear what kind of government regulation is required to support or control biotechnology (or even whether it could be controlled), and it appears that private-sector standardisation efforts have not yet emerged in any real way.

This leads us to the third tension, which is the tension between use and misuse of new technology. Dual use technologies are those technologies that 
can be used both for civil and military purposes. The "dual use" aspect of IT and biotechnology does not only concern a few applications. The features that make these technologies different also make the effects of their abuse potentially greater than those of other technologies. Yet, the level of control that is in the hands of the individual makes social governance much more complex than for technologies that require collective action to build, use, or maintain. In principle, all of IT and biotechnology can be used both for civil and military purposes. The use of the Internet for crime and the misuse of the network by public and private groups in ways that invade personal privacy is in the limelight of the public debate. This holds true also for risks entailed by biotechnology. The knowledge needed to weaponise a germ is essentially the same that is needed to understand how that germ causes disease and how to create an effective vaccine against it. In principle, the sole guarantee against IT and biotechnology misuses would be a time gap between the new discovery and its technological applications. This time gap would allow to activate mechanisms of self-regulation and internal checks within the scientific community. But it is this gap that cannot exist any longer. As an industrial enterprise IT and biotechnology cannot afford any delay in commercialisation.

New questions will be raised as biological sciences and computer sciences converge into applications called bioinformatics. As science explores creating information technology that can be used as a human prosthetic, questions about when it is appropriate to use these technologies and under what conditions will arise. Science is also exploring the use of biological materials as information processors in objects, such as "biochips". Technologists suggest that miniature biological sensors detecting chemical and biological information may soon be available that will be capable of providing instant feedback on individual or group activities and, further, of linking this information into ultra-scale networked computing. How can abuses of these technologies, such as surveillance and large-scale information-gathering among the population, be anticipated and regulated or countered? How can terrorist groups, mafia cartels and other "rogue" actors on the global stage be prevented to misuse this technology?

\section{SCIENCE AND POLITICS}

One characteristic of post-modern technology is the radical change of the representation, value and status of science. Science has become more of a technique, and, aptly, there is the expression "techno-science". This emphasises operational ability and productivity, and the interaction of science, technology, economy and politics. The representation of science has 
changed so much that some people may say that: "doing science is another way for doing politics".

Government regulation and private-sector standardisation are highly active in IT and biotechnology arenas, although they have trouble keeping up with the pace of change. According to the old, elitist, model of governance, experts advise policy makers who then take decisions, while common citizens are not at all involved in decision making. It is clear that the evolution of IT and biotechnology itself has been making this old governance model inappropriate and even counterproductive. There are at least two main reasons for explaining this. First, the increasing importance of the media system - chiefly due to the information revolution - makes impracticable any form of elitist debate. Second, it has changed the public and political perception of expertise. Expert's knowledge is not available in a timely and readily useful form. Both public and policy makers perceive the scientific community as dispersed and fragmented: experts do not share the same view and any advisory committee ends up reproducing the same divisions that one can find in the society.

New governance mechanisms are needed. They should present three main features: (1) Internationality, (2) Pluralism, and, (3) Accountability.

First, it should be clear from the outset that any effort to create governance institutions for either of the two technology areas in question must be international. Modern information technology is inherently is without borders. The Internet user does not care about the physical location of any given server; so it is possible to defeat an effort by one nation or jurisdiction to control or close down a site by moving it to another nation or jurisdiction. Biotechnology is less mobile but still presents many of the same challenges: For example, if one country wants to ban cloning or genetic manipulation of offspring, people who want such things can simply obtain them in another country without such regulations. It is useless, therefore, to think about governance except in an international context.

Second, it should be clear that decision can be taken only according a pluralist model that involves a significant number of organisations and users in deciding what technologies to support with research and development funds. In addition, what technologies need governance, what the norms of use and application should be, and whether they should be regulated; and, if so, how, and at what level of formality. Researchers and policy makers cannot be the sole actors on the stage. Researchers are under increasing pressure to demonstrate the policy relevance of their findings and to deliver tangible results. In turn, policy-makers are under increasing pressure to justify their choices of technology to be developed and socio-economic goals to be pursued. Thus NGOs, consumers' associations, citizens' panels, should be directly involved in decision making through instruments such as consensus conferences, voting conferences and scenario workshops. 
Third, given that NGOs, consumers' associations, citizens' panels base their authority primarily on the voluntary choices of their members, this raises issues of legitimacy. In other words, we cannot imagine to substitute democratic procedures with "survey" techniques. It means that we need to define accountable, transparent, open and effective procedures that may bring together scientific expertise, technological assessment, democratic representativeness, and policy making.

\section{ACKNOWLEDGEMENTS}

This work was funded by a grant from the European Commission - DG Research - Contract nr QLG6-CT-2002-01796 (Bioethical Implications of Globalisation Processes).

\section{REFERENCES}

CERFE, 2003 Glocalisation. Research, Study and Policy Reccomandations, Available at: http://www.glocalforum.org/New_Glocal_Website/ttank/ttank.html)

Commission of the European Communities, 2001, European Governance: a White Paper.

Foster, J., 2003, What is the GRID?, available at: http://wwwfp.mcs.anl.gov/ foster/Articles/WhatIsTheGrid.pdf

GDRC - The Global Development Research Centre, Understanding the concept of Governance, online: http://www.gdrc.org.

Koenig, M. 1999, Religion, Multiculturalism and Democracy - the contribution of international social sciences, Opening Address, The Second Religion and Cultural Diversity Conference, London, $31^{\text {st }}$ October, 1999. 